\title{
LA ESCRITURA EN MOVIMIENTO DE VALERIA LUISELLI: DEL PASEO SOLITARIO A LA VENIDA DEL OTRO
}

The Writing in Movement of Valeria Luiselli: from the Solitary Walk to the Coming of the Other

BERnAT Garí BARCELÓ

Universidad de barcelona (barcelona)

bernatgari@hotmail.com

Orcid: https://orcid.org/0000-0001-6744-8115

DOI: https://doi.org/10.5565/rev/mitologias.793

vol. 23 | junio 2021 | 103-117

Recibido: 31/03/2021 | Aceptado: 19/05/2021

Resumen

El propósito de este trabajo es inscribir en un mismo recorrido el conjunto de narraciones de Valeria Luiselli. Para ello, después de esbozar un panorama de los artículos dedicados a su narrativa, me centraré en demostrar que el denominador común que articula sus obras alrededor de un mismo segmento no es otro que el de la sujeción de la escritura a una lógica móvil a través de la cual se avanzará desde una reescritura del flâneur y un movimiento solitario, en las primeras novelas y ensayos; a un movimiento de acogida y amparo, cuyo punto de referencia es la crisis política de los refugiados, en sus dos últimos textos.

Palabras clave

Valeria Luiselli, crisis de los refugiados, flâneur, movimiento 


\begin{abstract}
The purpose of this article is to lay out the thematic through line of Valeria Luiselli's narrative work. After providing an overview of the articles dedicated to her writings I will demonstrate that the common denominator, which binds her works together, is the subjection of writing to a mobile logic. This logic advances from a rewriting of the solitary 'flâneur' in her first novel and book of essays, to a movement of embrace and sheltering in her two most recent works, those that center around the political refugee crisis.
\end{abstract}

\title{
Keywords
}

Valeria Luiselli, Refugee Crisis, Flâneur, Movement

\section{Escritura y movimiento. La propuesta narrativa de Valeria Luiselli}

En un artículo de 2019, titulado "La mirada aérea de la flâneuse: el paisaje vertical en Papeles falsos y 'Swings of Harlem' de Valeria Luiselli', María Paz Oliver examina la fuerte impronta que Papeles falsos (2010), la primera obra de Luiselli, dejaría en el recorrido futuro de la autora. El análisis de esta obra, de sus mecanismos y estrategias retóricas, da cuenta de dos o tres rasgos que en Los ingrávidos (2011), Los niños perdidos (2016) o Desierto sonoro (2019) adquieren consistencia física, tangible. Oliver destacaría, en la línea también de Liesbeth François (2019), el carácter móvil de la escritura de la autora, su trabajo con los límites telúrico-identitarios (geográficos, culturales, nacionales, etc.), que hacen de Luiselli una escritora "glocal" (Mora, 2014) o posnacional (Castany, 2007), e insiste en la elaboración de una "mirada aérea" reformulada del flâneur de Benjamin y Baudelaire.

Unos años antes, María Pape, en un artículo sobre Los ingrávidos, inserta la propuesta de Luiselli en una línea de producción 'radicante' (Bourriaud, 2009) y destaca, de nuevo, el carácter móvil de sus procedimientos, esta vez en relación con el montaje visiblemente aleatorio de la obra —reordenado por Licata en otro lugar (2019). El texto, que amasa voces localizadas en épocas y escenarios distintos, funciona como nexo, como anclaje, de dos cronotopos que, de modo progresivo, confluyen en el espacio de la página: "la novela se construye como el vaivén de fragmentos entre dos líneas narrativas distintas, pero relacionadas entre sí [...] detrás de esta aparente inmovilidad se articula la movilidad. En el salto de fragmento a fragmento, la novela misma se mueve" (Pape, 2015: 173). La narración, como no deja de consignar una de esas voces, ha de leerse en clave armónica, desde la perspectiva vertical que condicionó la escritura de Papeles falsos: "No una novela fragmentaria. Una novela horizontal, contada verticalmente" (Luiselli, 2019: 74). Los márgenes espacio-temporales, en Los ingrávidos, prefiguran "el espacio por excelencia de la ingravidez, la ligereza, el movimiento, en fin, la liquid modernity [...] definida por Zygmunt Bauman” (Berghe y Licata, 2020: 163).

También La historia de mis dientes (2013), aunque no tematice la historia de un viaje, por más que retome el esquema de la picaresca, ha sido descrita como "forma errante" (Amaro Castro, 2017: 10), por su marcado carácter híbrido y polilógico (Ette, 2015). Se trata de una obra en marcha, fruto de una construcción colaborativa autor-lector (Ramírez, 2018: 334) que no pretende clausurar en ningún punto el significado de lo que narra. 
Finalmente, Los niños perdidos y Desierto sonoro, el punto de llegada, hoy por hoy, de la obra de Luiselli, han generado una abundante bibliografía centrada en un movimiento de acogida, en el que un otro infinitamente otro, el refugiado, es quien viene hacia nosotros, quien deja caer, como diría Derrida, todo su peso sobre mí. Morales Muñoz, por ejemplo, bosqueja, desde el marco de reflexión de Cornejo Polar y Edward Said, los distintos rostros del proceso migratorio para reseñar los pasajes más significativos de Los niños perdidos. También Ilse Logie señala ese movimiento de venida: "la vertiente personal, tan presente en los otros libros de Luiselli, parece enmudecer [a partir de Los niños perdidos] ante la enormidad de los hechos y ante la autoridad con que estos hechos pueden ser representados por informes sin adornos" (2020: 105). Cito, también, un artículo reciente en el que he remarcado la naturaleza necesariamente aporética de estas últimas obras (Garí Barceló, 2021) en las que se asume que la crisis de los refugiados solo se puede abordar desde un movimiento ininterrumpido, pues la llegada del otro, diría Derrida, nunca cesa de recomenzar.

Valdría la pena detenerse, también, en los diálogos que Luiselli mantiene con Enrique Vila-Matas, no únicamente porque den cuenta de una filiación — con Bolaño, Pitol, Duchamp, etc.—, sino porque ahí se perfilan las interioridades creativas de la autora y su vocación transnacional pensada desde la asunción de un paradigma identitario móvil, menos esencialista, previa renuncia a la matriz estáticoidentitaria vinculada a la modernidad (Espacio Fundación Telefónica, 2019).

Luiselli es, como referiría Bourriaud, una "semionauta", ya que en su proyecto el sujeto es, en última instancia, movimiento, no por una decisión tomada a consciencia, sino por los ritmos hiperacelerados que impone el contexto de la globalización —ahí quedan las reflexiones fundamentales de Bauman, Lipovetsky, Byung-Chul Han o Baudrillard sobre el asunto. Unos ritmos que han vuelto la vida invivible, que han secuestrado el mundo, y que desfiguran cualquier pretensión utópica de una casa o un refugio. Cómo reaprender, pues, el mundo será una de las interrogaciones que nuclean las distintas propuestas de la autora.

Hacer balance de la creciente producción crítica que sobrevuela la prosa de Luiselli descubre que muchas aproximaciones teóricas comparten un campo semántico ("flâneur", "refugiado", "exiliado" son palabras talismán que aparecen en los escritos mentados) y, también, una hipótesis semejante: el movimiento parece indesligable de la escritura de Luiselli sea porque es tematizado en el plano explícito de la diégesis, en las figuras del flâneur o el migrante, o, simplemente, porque esta piensa su escritura en términos de "obra en marcha" con la que no pretende agotar el sentido de lo que narra, como lo prueban, por cierto, las constantes reescrituras a las que somete su producción. Así, esta lógica móvil contagia las dinámicas escriturarias de Luiselli hasta el punto de que el propio dispositivo de construcción de sus textos acaba por incorporar la posibilidad misma del movimiento.

"Movimiento" es una palabra dúctil que nos dará mucho juego si la trasladamos al ámbito de la filosofía y la literatura, como ya hicieron, desde distintos espacios, Ottmar Ette (2008; 2015), Graciela Speranza (2012) o Nicolas Bourriaud (2009), y que remite a un conjunto heterogéneo de operaciones retóricas que podríamos sistematizar en función de su alcance y su poder de penetración en el tejido textual:

1. En un primer nivel, el más elemental, se situaría el viaje, la tematización de un recorrido Bajtín hablaría de un "cronotopo del camino" (1989: 394-395). En Luiselli, "ya sea desde la ficción o el ensayo, el vínculo entre literatura y viaje es una constante" (Oliver, 2019: 14). Constituye este, por su explicitud, el nivel más evidente, es decir, el movimiento como tema o secuenciador del sentido que determina, en última instancia, la estructuración de la obra y la colocación de sus pasajes.

2. En un segundo plano, más estilístico, se situarían esas operaciones que sabotean el lenguaje en su dimensión morfosintáctica y, a veces, léxica. Frente a las formas más reposadas del 
registro estándar y las articulaciones más cerradas del lenguaje académico y periodístico, la fragmentación del texto, el uso de marcas disruptivas, la invención de neologismos o la mezcla de registros funcionan como operadores contradiscursivos que desautomatizan el discurso para alejarlo de sus usos más fosilizados; hacen, en definitiva, que el lenguaje se ponga en movimiento y asuma una función performativa. No en vano, Roland Barthes, en sus seminarios, dijo que la lengua es fascista porque nos obliga a un 'decir' fomentado a través de los dispositivos de control y disciplinamiento, frente a la literatura que constituye un escenario de resistencia y experimentación capaz de posibilitar un desvío del "fascismo del lenguaje" (Barthes, 2007: 57).

3. En un último nivel, más integral, se asume el movimiento como condición de posibilidad de la obra misma, como fenómeno indesligable de la escritura, frente al concepto de "novela total" u obra acabada. El inacabamiento, pues, como seña identitaria, y la asimilación de un formato de escritura abierto e inarticulado, tal como lo pensaron Susan Sontag (2007: 222) o Umberto Eco (1990), constituiría este último nivel de análisis.

La aparente falta de organicidad de la obra de la autora puede articularse alrededor de ese segmento, es decir, sometiendo la técnica narrativa a una lógica móvil, a una línea de reflexión "radicante", que admita que el sentido o la significación no son solo posibles desde el arraigo, el reposo o las grandes articulaciones narrativas, sino que, todo lo contrario, la experiencia del vivir se hace más visible desde una semiótica del desvío, desde una escritura que se transparenta en el espacio de la página a través del movimiento: fragmentación, desplazamientos entre géneros y disciplinas, desestabilización de cronotopos estático-lineales, etc.

Valeria Luiselli, en definitiva, se desplazará de un movimiento meditativo y nostálgico, en Papeles falsos o Los ingrávidos, que tiene en Poe, Baudelaire, Walser y, sobre todo, en Benjamin un punto de referencia, a un movimiento generoso, de acogida y amparo, en Los niños perdidos y Desierto sonoro. Su propuesta se concreta en una interrogación concisa: ¿cuál es la ley del movimiento?, ¿qué se pierde o qué se gana en un mundo visiblemente lastrado por la caída de los fundamentos y en el que apenas permanece el gesto fantasmático de un sujeto sin puntos de referencia?

Para Luiselli, como mostraré, solo un movimiento pausado y reflexivo posibilita la restauración de un mundo inmerso en la lógica de la aceleración, pues únicamente este puede combatir el borrado de sentido para avanzar hacia una recuperación de la experiencia o, por qué no, de la compañía y del rostro vulnerable de quien sufre.

El movimiento deviene en una hermenéutica de la recuperación con la que será posible salvaguardar un mundo desaparecido en sus dinámicas hiperaceleradas. Más aún, el movimiento, como marca textual, constituye un arma política, asumida desde el flâneur, el refugiado o el migrante, para denunciar los excesos de la biopolítica en las sociedades tardocapitalistas.

\section{Niveles del movimiento en Papeles falsos, Los ingrávidos y La historia de mis dientes}

Papeles falsos, Los ingrávidos y La historia de mis dientes conforman el primer arco de textos en el que el movimiento, a través de la figura del paseante y de un proyecto de escritura fantasmático, que tiende a la disgregación y a la fragmentación del espacio genérico, se convierte en seña identitaria de la narrativa de la autora. 
Papeles falsos, el primero de la serie, es un texto híbrido, que condensa un movimiento permeado por la soledad y la nostalgia de quien anda. La colocación de estos "ensayos narrativos" (González Arce, 2016: s.p.), que amasan autoficción, filosofía, ensayo y novela, pese a su aparente falta de unicidad, responde a una voluntad de someter a examen la mirada del paseante, de pensar su límite, para avanzar, más allá de lo visible, a una crítica al universo referencial de las sociedades tardocapitalistas. Como ha indicado Liesbeth François, Luiselli asume el ocaso del modelo del flâneur, su agotamiento, y se abre camino a una reformulación de la "caminata urbana": "Papeles falsos [...] se convierte en búsqueda de alternativas: retoma la desestabilización como valor no problematizado en sí, y explora maneras de actualizar una poética de la deambulación urbana [...] reconectándola con otras formas de movilidad citadina, como la bicicleta y el avión” (François, 2019: 869). Se progresa, así, del primer texto al último, hacia el deslinde de una escritura móvil, cuestionadora de los encuadres y estrategias de la narrativa realista, de las matrices genéricas tradicionales incluso, que sea capaz, en última instancia, de restituir el sentido de una época malograda por la velocidad y la tecnificación de la realidad.

Luiselli reformula el flâneur, figura íntimamente vinculada a la modernidad, pero esta vez, aunque la filiación con los escritos de Poe, Walser, Baudelaire o Benjamin, citados muy de seguido a lo largo de la obra, es notoria, la mirada de la narradora se enfrenta a un mundo globalizado: a la "aldea global". Por ello, redirige sus materiales de lectura hacia ese nuevo horizonte espaciotemporal para rearticular la manera de mirar del paseante, lo que adhiere nuevas capas de significación a la perspectiva clásica asumida por Baudelaire, Walser o Benjamin. En bicicleta, en avión o a pie, arrogándose muchas veces el rol ocioso de quien turistea, la narradora reconoce que, en este mundo, solo se "es" paseando: "uno no viene de parte de nadie [...] sino que uno está paseando, sólo paseando" (Luiselli, 2020: 76). El sentido queda íntimamente entrelazado con los itinerarios azarosos que dibuja el paseante posmoderno, el "radicante", inmerso en el espectáculo de un mundo en el que los viejos puntos de referencia amenazan con desaparecer. La escritura urbana de Luiselli traduce un movimiento constante de búsqueda, de exploración, a través de un lenguaje que recorre el paisaje mientras interroga sus propias condiciones de posibilidad. El texto cuestiona a cada punto la noción benjaminiana de experiencia y trata de captar, en los intersticios — callejones, lugares de paso, no-lugares—, en la línea de El libro de lospasajes, de Benjamin, los espacios de reposo, de calma y de tranquilidad que no han sido absorbidos por las dinámicas de la aceleración. Parece, pues, que la narradora se compromete, a la manera de Ottmar Ette (2008), con una ontología del desplazamiento, y se abre paso, a su vez, impelida por las circunstancias sociopolíticas, a una reformulación del concepto de "paseo":

los apologistas del paseo han enaltecido el acto de caminar al punto de convertirlo en una actividad con tintes literarios. Desde los paripatéticos hasta los flâneurs modernos, se ha concebido la caminata como poética del pensamiento, preámbulo a la escritura [...]. Pero lo cierto es que ahora, en la poca caminable y apenas literaria ciudad de México, el peatón no puede salir a la calle con el mismo buen ánimo que declaraba Robert Walser al inicio de su paseo. (Luiselli, 2020: 39)

El flâneur siempre fue un buen barómetro para diagnosticar los cambios e inquietudes sociales flotantes en el ambiente; fue un "figura-bisagra" (Verdú Arnal, 2013: s/p.), un punto de encaje entre la primera modernidad y la modernidad tardía. Papeles falsos proyecta dicha figura más allá de su contexto originario para repensar su viabilidad, sus condiciones de gestación, en el contexto de un mundo sometido a incesantes transformaciones, y que no puede abrirse paso más allá de su presente y de su punto de partida.

La paseante de Papeles falsos siente apenas la tierra que pisa y el destino de su voz aparece ligado a la pérdida y la diseminación de los límites —espaciotemporales, afectivos, ideológicos, etc_-, y a la articulación de un nuevo paisaje con una importante carga simbólica. Lo que capta la paseante, más allá de la variedad de objetos sobre los que posa su mirada - las lápidas del cementerio de San Michele (Luiselli, 2020: 15), unos planos consultados en la mapoteca (25-35), etc.—, es la experiencia de la pérdida, 
no solo la pérdida de los lazos afectivos, de la compañía, la historia y la memoria, sino pérdida en un sentido holístico; en concreto, pérdida del mundo.

Luiselli se inscribe, así, en una fecunda tradición que, desde principios del XX, ha entonado una reflexión sobre la pérdida del mundo (Foessel, 2013). En Heidegger, evidentemente, la pregunta sobre el ser era un indicio de que nuestra relación con el mundo se había empezado a desvanecer; Benjamin habló de pérdida e incomunicabilidad de la experiencia; Baudrillard, de suplantación de la realidad; Kafka, Camus o Beckett, de pérdida de Dios, del sentido. Luiselli, lectora de Benjamin, Heidegger, Kafka y Beckett, quienes conforman, entre otros, el tejido referencial de Papeles falsos, tematizará, también, la pérdida del mundo, de la experiencia, desde la óptica de un nuevo flâneur:

Los paseos solitarios de Rousseau, los vagabundeos de Walser o Baudelaire, las Bildergänge o las caminatas -imagen de Kracauer-y las flâneries de Benjamin fueron una manera de entender y retratar la nueva estructura de las ciudades modernas. Pero los habitantes de la ciudad de México [...] carecen de todo punto de referencia. Se perdió, en algún momento, la noción de un centro, de un eje articulador. (Luiselli, 2020: 33)

De este modo, ahí donde Luiselli parecía coincidir con Baudelaire, Poe o Benjamin, a su vez, se separa, se produce un desvío — un "clinamen", como diría Harold Bloom, es decir, una modulación, una sutil variación. El mundo ya no es mundo, ya no puede ser registrado desde la mirada de quien se pierde, según itinerarios aleatorios que escapan a cualquier plan de sistematización racional, en el interior de la gran ciudad. El nuevo paseante ya no es el mismo que el que surge a resultas del auge de la ciudad industrial, porque su universo referencial es, también, otro. Como indica Bourriaud, en la actualidad "captar la ciudad en una imagen sería más bien seguir su movimiento" (2009: 111). Ese es el imperativo que recorre el proyecto de Papeles falsos: deshacerse de los encuadres, adaptar la mirada del paseante a la velocidad de los nuevos tiempos, seguir rastros en un espacio urbano hipersaturado de referencias simbólicas y publicitarias, no con el ánimo de adecuarse a los nuevos escenarios que impone la globalización, sino con la voluntad de dominar y neutralizar, en la línea de algunas obras performativas de Doug Aitken o Francis Alÿs, la aceleración capitalista. Se logra, de este modo, una apertura de la mirada mayormente visual (¿empírica?) del flâneur a una mirada teórica y reflexiva (Oliver, 2019: 24), que se demora en lo conceptual, que permanece, como el flâneur de Vila-Matas, "en el umbral de la literariedad, esto es, en la conciencia de lo narrativo" (Verdú Arnal, 2013: s/p).

Este trabajo constante de adaptación de la mirada funciona como máquina de lectura anticapitalista, contra el reposo del "final de la historia" y la homogeneización del espacio-tiempo como los pensó Fukuyama, en 1989, en su relectura en clave hegeliana de la historia occidental. De nuevo, Bourriaud, en sintonía con Luiselli, cifra en la errancia del flâneur la posibilidad de asentar el germen de algún tipo de revuelta:

la errancia representa pues una interrogación política de la ciudad. Es escritura en marcha, y crítica de lo urbano considerado como la matriz de los guiones en que nos movemos [...]. La errancia, como principio formal de composición, remite a una concepción del espacio-tiempo que se inscribe a la vez contra lo lineal y contra lo plano. (2009: 115-116)

Luiselli piensa en contra de las dinámicas hiperaceleradas del capitalismo financiero, en contra del exceso dataísta y referencial (al que se alude, también, en la citada entrevista con Vila-Matas), en contra de la pérdida de lo humano, con el propósito de recuperar, en la línea de Poe, una intimidad fructífera entre el gentío. La cuestión no es meramente cognoscitiva, sino que se desplaza al plano de lo político y de la existencia: ¿cómo reaprender el mundo para habitarlo de otra manera?

Uno de los movimientos que se describen es el de recogimiento, traducido en aislamiento, en soledad fructífera. El flâneur ya no puede ejercer como espía o voyeur porque la lógica que impone la 
digitalización ha diseminado la posibilidad de su mirada: "las computadoras personales, a estas alturas ya lo sabemos bien, son el gran atentado moderno contra el voyeurismo" (Luiselli, 2019: 92). Parece que lo digital suprime, entonces, la esfera de lo privado. No ocurre únicamente, como indicó Lipovetsky (2015), que la res pública haya sido arrumbada por la hiperinversión en el "yo"; en todo caso, lo frontera entre lo público y lo privado ha sido licuada y sustituida por un paisaje digital en el que lo privado coincide con lo público.

Por ese motivo, la flâneuse de Luiselli se sitúa en los pliegues, en los intersticios entre lo público y lo privado —en ese cronotopo de una intensa carga emotiva que Bajtín denominó "cronotopo del umbral" - para obrar otras formas de restituir la experiencia de lo humano:

un portero [se ratifica en el texto "Otros cuartos"] es dueño del espacio más privilegiado en este mundo. Erguido frente a la fachada de su edificio o postrado en una silla de la recepción, el portero es un guardián, el último Cerbero, que custodia los límites imprecisos entre el mundo de lo público y de lo privado. Solo en aquel pórtico liminar y bajo el cobijo de su vigilancia, nos sentimos a salvo de las claustrofóbicas categorías del afuera y el adentro. (2020: 96)

Esos escenarios, pues, en los que se vive como "de paso", los "momentos umbral" (2005: 460), como los llamaría Benjamin, facultan otros gestos y afectos que no han sido absorbidos por la lógica capitalista. De ahí que la narradora reformule esa máxima socrática, extrapolada del templo de Apolo, en Delfos, para configurar su propio ethos: "todos deberíamos participar de cierta poligamia habitacional y dormir las más veces posibles en camas ajenas, si queremos ser de veras fieles al llamado milenario: conócete a ti mismo" (2020: 95). ¿Cómo escapar, pues, a la ley capitalista de la aceleración? A través del movimiento, a través de un movimiento sosegado, ininterrumpido, como desinteresado, que capte en los intersticios la posibilidad humana del contacto.

Otro movimiento que, también, apunta a la recuperación de la soberanía del paseante lo ha detectado Oliver, quien defiende la presencia de una "perspectiva aérea" en varios textos de Papeles falsos para ampliar la mirada más clásica asumida por el flâneur. La narradora, en "La habitación y media de Joseph Brodsky" o "Mancha de agua", admite estar observando como desde arriba (desde un aeroplano, persiguiendo rastros en un mapa): "vista desde un avión, la isla del cementerio podría parecer un enorme libro" (Luiselli, 2020: 15).

Como sugiere Oliver, todos estos recursos permiten pensar en clave femenina la figura del flâneur. La autora no trabaja desde la perspectiva de un paseante que se abre paso en el espacio heterogéneo de la gran ciudad para deleitarse en lo inesencial, en la pura contingencia, sino que elabora otra perspectiva; la de una flâneuse, que se demora en su andadura, que ensaya un deambular paciente, digresivo, con un movimiento pausado que desacelera los ritmos urbanos.

Estos movimientos se trasladan, a su vez, a un segundo nivel, más retórico, centrado en el trabajo con el lenguaje. La correlación entre ciudad y lenguaje se pone de manifiesto en varios ensayos, pero en "Relingos" adquiere cierta centralidad: "se ha comparado muchas veces a las ciudades con el lenguaje: se puede leer una ciudad, se dice, como se lee un libro [...]. Los paseos que hacemos a lo largo de las lecturas trazan los espacios que habitamos en la intimidad" (2020: 77-78). La indagación de la narradora se inserta en esa línea de reflexión posmoderna que trata de licuar la frontera realidad/ficción para insistir, de nuevo, en que reaprendemos la realidad a través de la literatura. La ciudad es solo un pretexto para indicar, a la manera del primer Wittgenstein, que el límite del lenguaje es el límite del mundo, que nuestra aprehensión de la realidad está sujeta a la materia verbal, y que reaprender la tradición literaria permite habitar un presente que se desvanece, pero que podemos reapropiarnos designándolo con otras palabras. Las menciones a Wittgenstein, además de otros precursores del giro lingüístico, son, de hecho, una constante de Papeles falsos. 
Se insiste, pues, en la necesidad de repensar los límites de la ciudad/lenguaje para situarnos en ellos, en la frontera entre lo decible y lo indecible, con la voluntad de construir una nueva subjetividad. La mirada de la paseante no solo recorre el paisaje, sino que se recorre, se autorrefiere, para reflexionar sobre el movimiento y el lenguaje que lo acompaña; se sintetizan, así, la forma y los contenidos.

Por ello, las geografías liminales, objeto de reflexión en "Otros cuartos", mediatizan las operaciones retóricas de la narradora cuando trata de avanzar hacia un lenguaje que se instale en esos intersticios; un lenguaje que no se agote en la pretensión utópica de colmar los silencios que impone el límite, sino que se demore en ellos para reflexionarlos, reflejarlos, desde la posición humilde de quien espera poca cosa o, tal vez, con el ánimo de aprender a habitarlos sin crispación: "No, escribir no es rellenar huecos (construir una casa, un edificio, en un espacio vacío, tampoco lo es necesariamente) [...] Escribir: taladrar paredes, romper ventanas, dinamitar edificios. Excavaciones profundas para encontrar —¿encontrar qué? - no encontrar nada. /Escritor es el que distribuye silencios y vacíos" (Luiselli, 2020: 78-79).

Estos elementos se concretan en la que sería stricto sensu la primera novela de la autora, Los ingrávidos, un texto que, según Berghe y Licata, es una novela en marcha, "una novela baciéndose cuyo novelar se comenta en el mismo momento de escribirla" (2020: 162; cursivas del original). El texto no retoma de manera tan explícita la figura del flâneur, más allá de algunas alusiones puntuales (Luiselli, 2019: 118), pero acciona, en varios niveles, un conjunto heterogéneo de operaciones definidas por la lógica móvil de la primera obra.

Como ha subrayado Pape, enfatizando la correlación Cortázar-Benjamin-Luiselli, los espacios liminales, las transiciones, son, también, el cronotopo privilegiado en la novela: "la movilidad funciona como una condición fundamental para la construcción de Los ingrávidos. Solo que en vez de tomar al viaje como imagen, la movilidad parece tomar la forma del pasaje, dada la falta de interés por la trayectoria y el énfasis en un pase más directo entre lugares" (Pape, 2015: 173-174). Se asientan, pues, las condiciones de formulación de una poética de los umbrales, como marca de época, que permite definir la errancia posmoderna y la intangibilidad de determinados espacios, previa asunción, en Papeles falsos, de que solo hay vida en los intersticios.

La condensación de planos diegéticos, consignada por Pape (2015), González Arce (2016) o Licata (2019), que anudan la época en la que el poeta Gilberto Owen vivió en Nueva York y el presente narrado por la protagonista, es formulada de manera intersticial: será en los lugares de paso — en el metro, sobre todo- en donde los planos narrativos se interseccionan y facultan un diálogo transhistórico. La narradora, de hecho, asume de nuevo el movimiento como procedimiento escriturario, en este caso, no desde la correlación escritor-paseante, sino desde una concepción de la escritura como viaje en tren: "si te dedicas a escribir novelas, te dedicas a doblar el tiempo. Creo que más bien se trata de congelar el tiempo sin detener el movimiento de las cosas, un poco como cuando uno va subido en un tren, viendo por la ventana" (Luiselli, 2019: 118). Esta perspectiva móvil, obrada como "viaje en tren", coopera en la neutralización el cronotopo estático-lineal de la novela realista tradicional y exacerba un dialogismo entre épocas y escenarios.

De ahí que, a lo largo del texto, no se deje de trazar un itinerario de lectura que invoca la perspectiva armónica de la obra anterior: "Nota (Owen le escribe a Celestino Gorostiza): “A New York se la empieza a ver desde el subway. Acaba allí la perspectiva plana, horizontal. Empieza un paisaje de bulto ahí, con la doble profundidad, o eso que llaman la cuarta dimensión del tiempo" (Luiselli, 2019: 44). La horizontalidad de la trama, que reproduce la tríada planteamiento-nudo-desenlace, ha de ser complementada con una mirada vertical que observa la ciudad como desde abajo, desde el metro, es decir, esta vez desde una "mirada subterránea" que invierte la focalización de ensayos como "Mancha de agua" o "La habitación y media de Joseph Brodsky", en Papeles falsos. Esa otra mirada, crispada en lo 
teórico, vislumbra las sedimentaciones y rastros que los espectros del pasado han ido dejando en sus recorridos por los escenarios del presente.

En Los ingrávidos, se dibujan también los contornos de un viaje, de un movimiento de búsqueda, una búsqueda que no clausura su itinerario y que, simplemente, trata de forjar una reflexión sobre el lugar que ha de ocupar el escritor contemporáneo en su lectura y reescritura de la tradición. Como muchos procesos de búsqueda, esta empieza con una iluminación, con una situación-acontecimiento, que tiene lugar en otro espacio intersticial, en un momento en el que la narradora, en el trance entre la vida y la muerte, en ese límite entre realidad y sueño, entra en contacto con el fantasma de Gilberto Owen. De ahí que, para Pape, un cuento como "La noche boca arriba" de Cortázar, o el Libro de los pasajes de Benjamin, sean intertextos relevantes para definir estas situaciones-umbral.

A partir de aquí será en el metro donde se produzca el ensamblaje entre escenarios: "el metro [dirá la narradora] me acerca a las cosas muertas" (2019: 65). La paseante que recorre estos escenarios se vacía de sí, se llena de las voces que pueblan el pasado y abandona la propia identidad para transmutarse en el testimonio dejado por escritores de otras épocas (Gilberto Owen, Ezra Pound, García Lorca). Se pretende, en el fondo, restaurar un mundo que se pierde; volver visibles (y vivibles) los espacios públicos, los callejones, las plazas de la ciudad desde la lectura y la reescritura: "los espacios públicos, como las calles y las estaciones del metro, se iban volviendo habitables a medida que les asignara algún valor y se les imprimiera alguna experiencia. Si yo recitaba un pedazo de Paterson cada vez que caminaba por cierta avenida, con el tiempo esa avenida sonaría a William Carlos William" (Luiselli, 2019: 26). La experiencia, pues, solo se recupera con una mirada que permea la realidad desde la cultura libresca, y así la desliga del ruido y de la saturación discursiva que colman los espacios públicos.

Los planos mencionados irán convergiendo, de manera escalonada, en la última parte de la novela, cuando la historia de Owen suplanta el nivel intradiegético de la narradora y se impone. Ambas épocas se vacían y van coincidiendo, punto por punto, en dos líneas paralelas que interaccionan especularmente. Lo que ocurre es que el borrado de la propia vida, maquetada en el dispositivo autoficcional de la primera parte, se va licuando en la autobiografía de Owen con la que se pretenden borrar los rastros y huellas que conducen al primer texto. González Arce expresa que "la narradora se ve a sí misma una suerte de Sherezade a la inversa, que hilvana sus relatos no para conservar la vida sino para acercarse a la muerte [...] para no sacrificar ninguno de los dos planos, la narradora opta por hacerlos convivir, como una Penélope esquiva" (2016: s/p). Resulta particularmente productiva la imagen de Sherezade, que evoca la relación entre escribir e hilvanar, ya que está ligada a los recursos que posibilitan la propuesta móvil de Luiselli. Fragmentación, multiplicidad, lentitud o reescritura son valores asociados a su idea de prosa.

Las dos líneas temporales se irán desplazando, no sin acentuar sus itinerarios coincidentes, hasta solaparse, en la parte final, en una única línea argumental: “¿Quién, de Owen y de la narradora, es el Doble? ¿Quién es el original? ¿Quién es el vivo? [...] Se podría cavilar infinitamente respecto a estas interrogaciones sin llegar a ninguna respuesta" (Licata, 2019: s/p) La vida de la narradora vuelve a quedar atrapada en los entresijos de la ficción, solo que esta vez el viaje escriturario no se produce únicamente en el espacio, sino también en el tiempo, en los encuentros fortuitos, por lo general en el metro, con los fantasmas del pasado.

Finalmente, La historia de mis dientes, la propuesta más vanguardista de Luiselli, la que ha tenido peor acogida entre la crítica mexicana (Amaro Castro, 2017: 4-9), es una hipernovela -un hipertexto, que diría Landow-, que se aparta de la perspectiva del flâneur para insertarse en una línea más experimental. Más allá de algunas alusiones puntuales a un escritor ficticio, Roberto Bálser, en homenaje a Walser, los mecanismos narrativos se definen por un viraje hacia la metaficción y la deconstrucción, eso sí, no se asume lo 'posmo' de manera aproblemática, sino que se procede a un desmontaje a lo bruto de su utillaje retórico con la voluntad de parodiar (y renegar) de sus clichés y excesos eruditos. 
Destaca, en todo caso, el montaje de la novela como obra en marcha, con una estructura móvil que ha ido variando en sus reediciones y traducciones. Como se señala en los agradecimientos: "cada entrega se imprimió en fascículos caseros que a su vez se distribuyeron entre trabajadores de la fábrica de jugos de Jumex [...] que se reunían por las noches en un cuarto del barrio de Santa María Tupetlac a leer en voz alta, comentar y criticar las entregas" (Luiselli, 2020b: 157). Da la impresión, pues, que el borrado, la reescritura, las correcciones, fueron resultado de una operación coral que hace inoperativa la distinción autor/lector, lo que permite, de nuevo, una toma de distancia con el paradigma estáticomonológico de la novela tradicional.

Las primeras obras de Luiselli ilustran, en definitiva, la relevancia que el movimiento desempeña en la delimitación de un nuevo espacio ideo-estético. El paseo es la huella más evidente de esa lógica móvil, un paseo solitario, de un caminante que redescubre el mundo (y se redescubre). A su vez, las marcas textuales, la fragmentación del espacio genérico y el trabajo con el lenguaje dan cuenta de una acentuada ruptura con la mímesis y la noción de novela realista tradicional. Ese movimiento se expande, desde la publicación de Los niños perdidos en adelante, a un movimiento menos solipsista, de acogida y amparo, que tiene fija la mirada en la presencia de quien llega.

\section{“Tell me how it ends". Los niños perdidos y Desierto sonoro o la venida ininterrumpida}

Las dos últimas obras de Luiselli constituyen un viraje hacia una línea de reflexión mayormente sociocrítica centrada en la crisis política de los refugiados. En este caso, la lógica móvil de su escritura se reorienta hacia la voz de los que vienen, de unos sujetos definidos por su pura negatividad (sujetos sin casa, sin patria, sin capacidad de testimoniar). La categoría "refugiado", como vieron Agamben y Derrida, es una categoría intempestiva, pues la presencia del refugiado, su materialidad, pone del revés mi ley, mis maneras aprendidas y automatizadas, mi forma de ser, pensar y hablar; viola, en fin, la comodidad en la que mi vida se halla asentada. La situación del refugiado es un límite, una transición, que

no admite la afirmación, sino solo la disyunción: acogida o deportación, reconocimiento u ostracismo, utopía o desencanto. De entrada, el refugiado ha quedado atrapado en una situación aporética que será la principal línea de reflexión de Valeria Luiselli en sus dos últimas obras.

De niños decíamos "casa" para indicar que estábamos a salvo del peligro, el refugiado no puede decir "casa" porque su figura se concreta en una huida ininterrumpible. "Aporía", "condición desplazada", "nómada", "no-lugar", "errancia", "intemperie", son palabras que permiten una aproximación al concepto "refugiado" como algo que se nos opone. (Garí Barceló, 2021: 355)

Pensar el movimiento del refugiado como fuga ininterrumpible y reconocer que su venida no cesará - por ahora, como mínimo, no se ha dilucidado ningún horizonte que ponga fin a dicha crisissupone asentar la cuestión en el interior de una lógica aporética, no solo porque la venida se inscriba en un recomenzar incesante, sino porque el refugiado, según la definición que he ofrecido, solo podrá ser entendido como exceso.

Los niños perdidos (un ensayo en cuarenta preguntas) (2017), ampliación de un texto en inglés, Tell Me How It Ends (2016), publicado un año antes en la revista Freeman's Literary Magazine (Logie, 2019: 104; Martínez, 2016), es la primera de las obras en donde cristalizan los distintos rostros de este problema. La autora opta por un montaje aleatorio, visiblemente fragmentado, cuyo único eje son esas cuarenta preguntas extrapoladas de los cuestionarios para niños indocumentados con los que Luiselli se familiarizó mientras trabajaba en las cortes migratorias. 
La disposición de los pasajes, mediatizada por un esquema pregunta-respuesta, es, en apariencia, arbitraria, pero, en el fondo, ofrece el itinerario de un viaje que podrá rastrearse desde un paratexto, el índice, en el que se recogen cuatro epígrafes: "I. Frontera", "II. Corte", "III. Casa" y "IV. Comunidad". Estos títulos son solo puertas de entrada que otorgan a los pasajes del ensayo una coherencia estructural, aunque constituyen, también, los indicios mínimos que permiten pensar la estructura de la obra como recorrido. Parece que el trayecto del ensayo ofrece, si consideramos el orden de los títulos, las claves para regresar a casa o, por qué no, para restituir el sentido de pertenencia a una comunidad y al mundo.

No solo la estructura de la obra incrusta una lógica en movimiento en sus interioridades, también el estilo, distanciado del tono nostálgico y conceptual de los otros textos, se reorienta hacia otra dirección. Ahora será necesario recomponer, reflexionar, reescribir la voz de los niños que relatan su travesía sin distorsionar su testimonio; evitar la recaída en el informe frío, mecánico, de las cortes migratorias: "todas las historias que se traducen en la corte acaban siendo generalizaciones de los relatos personales, distorsiones; toda traducción de las historias de los niños es una imagen fuera de foco" (Luiselli, 2019b: 43). La materialidad del propio lenguaje deviene en objeto de reflexión. Como ha observado Ilse Logie, "la mediación lingüística fue el desencadenante del libro, la complejidad de esta operación aparece constantemente tematizada en él. La traducción está presente en su génesis: le da forma” (2019: 106).

La narradora intensifica, entonces, la dimensión reflexiva y autorreferencial de su escritura. No se limita a dar forma a lo que el refugiado dicta, a pulirlo, sino que lo integra en un espacio de interlocución más amplio: ¿cómo reescribir unas experiencias que llegan como cortocircuitadas, llenas de huecos, sin malograr su singularidad?, ¿de qué manera eludir la trampa de la representación?, ¿cómo testimoniar por quien testimonia?

Se resiguen, así, los pasos de los niños hacia las cortes migratorias a través de un itinerario que se desdobla: se vislumbra, por un lado, de forma explícita, el horizonte futuro de una casa o una comunidad, de un desenlace feliz, siempre y cuando el testimonio ofrezca alguna clave que permita sostener su caso ante los tribunales; por otro lado, la propia escritura dibuja un proceso de búsqueda, expresado en un movimiento constante de dubitación, de avances y retrocesos. El trabajo con el estilo es indirecto y elíptico, tentativo, pero define ese otro viaje en el que el lenguaje se recorre. La narradora ofrece, de manera reiterada, rastros inconfundibles: "los niños que entrevisto pronuncian palabras reticentes, palabras llenas de desconfianza, palabras fruto del miedo soterrado y la humillación constante. Hay que traducir esas palabras a otro idioma, trasladarlas a frases sucintas, transformarlas en un relato coherente, y reescribir todo buscando términos legales claros" (Luiselli, 2019b: 15).

¿Cómo relatar la venida? Esta interrogación constante, omnipresente, define el espacio de un ensayo que se irá distanciando de los textos anteriores y que conforma, como señala Ramos, "una reflexión sobre el entre-lugar imposible de la traducción" (Ramos, 2017: s/p; cursivas del original). El movimiento se traslada de la radicancia del flâneur, del yo, en Papeles falsos y Los ingrávidos, al movimiento de quien viene y, sobre todo, al problema de cómo narrar dicha venida.

En esa búsqueda se avanza hacia una lógica de la concatenación, de la juntura, en la medida en que la ilación de los restos discursivos de distintos testimonios permitirá cristalizar ciertas "imágenesconcepto" (Garí Barceló, 2021: 359), por ejemplo, la imagen de un mapa, cuya fuente más evidente es el ensayo "Mancha de agua", en Papeles falsos. El mapa es lo que nos da orientación, lo que puede ofrecernos ciertas pistas sobre qué hacer o cómo movernos ante esta situación. La narradora, así, articula una cartografía que permite repensar el conjunto de los refugiados como herida humana, como comunidad sin casa y, de ahí, a un proyecto que reformule la idea de comunidad:

se me confunden y mezclan las historias que cada uno me va contando a medida que avanzamos por las preguntas del cuestionario, quizás porque, aunque las historias de todos ellos son distintas, cada una es un fragmento de una historia compartida más amplia [...] Si alguien dibujara un mapa del 
hemisferio y trazara la historia de un niño y su ruta migratoria individual, y luego la de otro y otro niño, y luego las de decenas de otros, y después la de los cientos y miles que los preceden y vendrán después, el mapa se colapsaría en una sola línea —una grieta, una fisura, la larga cicatriz continental. (Luiselli, 2019b: 44)

Como espacio psico-geográfico, esta línea inmaterial, dicha "grieta", funciona como contracara de una idea de "comunidad" que constituye el horizonte de reflexión del ensayo. En los últimos pasajes, en el capítulo tercero ("Casa") y el cuarto ("Comunidad"), la narradora tratará de abrirse paso más allá de esa imagen-concepto. Moviliza, para ello, una lógica aporética, que solo es visible a la luz de una lectura conjunta de los dos capítulos. El título de la versión en inglés, Tell Me How It Ends, alude a una pregunta que la hija de la narradora le hace a su madre al final de la tercera parte: "Dime cómo termina, mamá me dice. No sé. [...] A veces invento un final, un final feliz. Pero casi siempre nomás le digo: Todavía no sé cómo termina" (Luiselli, 2019b: 80). Los niños perdidos, sin embargo, no solo es un ensayo con un "final abierto" (Morales Muñoz, 2019: 68) incapaz de concretar una respuesta satisfactoria para la susodicha pregunta (Logie, 2019: 110), sino que es un texto necesariamente inacabado e inacabable. Su carácter inconcluso tiene relación, en definitiva, con el significado político de la obra.

La respuesta a dicha pregunta no consigue articularse de manera explícita, pero será reconducida en la cuarta parte cuando los estudiantes de la narradora deciden pasar de las palabras a la acción. El lenguaje asume, así, una dimensión performativa con el propósito de neutralizar la polaridad entre escritura y vida, entre pensamiento y acción. La acción es, sin embargo, inacabable, necesariamente aporética, como reconoce la propia narradora, sobre todo, porque la magnitud de la tragedia invita a un movimiento ininterrumpido de acogida y amparo. De ahí que, en la última página se nos instale, otra vez, frente a la primera pregunta del cuestionario (“¿por qué viniste a los Estados Unidos?”), no porque el itinerario de la obra se agote en un círculo perfecto, sino porque avanza a través de ciclos ininterrumpidos, inclausurables, que se abren paso de manera progresiva de la inacción a la acción, de la palabra al gesto, de un solipsismo enunciativo al reconocimiento del rostro de quien sufre.

Este esquema es reformulado en la última obra de Luiselli, Lost Children Arcbive (2019), traducida al español bajo el título Desierto sonoro, cuyo nexo con el ensayo Los niños perdidos ha sido remarcado desde distintas perspectivas (Dóñiz Ibáñez, 2019: 28; Garí Barceló, 2021: 361-363). La filiación, de entrada, se pone de manifiesto desde un peritexto, esta vez un epígrafe, que recoge la "oración del migrante" compilada en la parte final del ensayo: "Partir es un poco morir/ Llegar nunca es llegar definitivo" (Luiselli, 2019b: 88). La identificación con la obra anterior puede perseguirse desde distintos rastros: la mención de los niños refugiados como "niños perdidos" (Luiselli, 2019c: 186), la recodificación de varios pasajes de Elegías para niños perdidos, de Ella Camposanto, la ficcionalización de casos trabajados en el ensayo (Luiselli, 2019c: 30-31). El vínculo ha sido reconocido por la propia Luiselli, quien explica que la redacción de ambos textos pertenece a un mismo periodo de reflexión, con saltos que comunican el espacio de representación de una y otra obra (Meyer, 2019: s/p).

Sin embargo, la traslación más evidente es la que apunta a la armazón conceptual de la novela. Luiselli reformula, con Desierto sonoro, el problema de la incomunicabilidad de la experiencia de los refugiados, de los niños perdidos, y lo hace, de nuevo, al situar la reflexión sobre el lenguaje en el centro de su propuesta. Las pistas que siembra en su recorrido son múltiples y traducen el movimiento de un lenguaje en una búsqueda de sí: “¿Qué quiere decir documentar algo, un objeto, nuestras vidas, una historia? Supongo que documentar cosas - mediante el lente de una cámara, en papel, o con una grabadora de audio - sólo es una forma de añadir una capa más, algo así como una pátina, a todas las cosas que ya están sedimentadas" (Luiselli, 2019c: 75).

La narradora admite el imperativo de contar, de rehacer, la experiencia de la pérdida, aunque esa experiencia sea siempre "una experiencia menos uno" (2019c: 130), es decir, una (re)presentación, en algún punto ciega, incapaz. Sin embargo, la irrecuperabilidad de la experiencia — las de aquellos niños, por 
ejemplo, perdidos en el desierto- puede rehacerse desde la lógica del collage, el simulacro y la juntura. Los cruces discursivos que amasa el tejido referencial de la novela (rumores fantasmáticos, sonoridades perdidas, testimonios imaginados) pueden producir destellos de significación que trazan un arco hacia el presente para recomponer la experiencia perdida:

un documento de una experiencia es igual a una experiencia menos uno. Lo extraño es esto: si un día, en el futuro, sumas todos esos documentos otra vez, lo que resulta, una vez más, es la experiencia. O al menos una versión de la experiencia que reemplaza a la experiencia vivida, incluso si lo que documentaste en un inicio fueron los momentos sustraídos a la experiencia. (2019c: 130)

Se señala de este modo un doble camino: el de la recuperación de la experiencia, "una experiencia menos uno" (2019: 130) tal vez, pero una experiencia, al fin y al cabo; y el de una sanación de las víctimas a través del discurso. Puede que la materia prima sean apenas un conjunto de restos discursivos, de rumores, pero esa secuencia de voces quebradas y espectrales, de vacíos semánticos, de "partes faltantes sustraídas del momento en que la experiencia tuvo lugar" (2019: 130), neutralizan el olvido.

Desierto sonoro, como ocurre con el resto de las obras de la autora, también integra el movimiento en el dispositivo de construcción del propio texto. La novela realiza una desmitificación del road trip norteamericano, pues, pese a las múltiples alusiones a la novela On the Road (1957), de Jack Kerouac, el recorrido no es alegre ni distendido, sino un recordatorio, un archivo elegíaco, un réquiem que recoge la voz de los que ya no están, de las víctimas exterminadas en el pasado (y en el presente) por la política estadounidense: apaches, refugiados e inmigrantes en general. El montaje referencial de la novela no discrimina dichas voces, sino que las mezcla, del mismo modo que en Los ingrávidos, en un viaje no reductible al espacio, sino integrado en el interior de un sistema más armónico que enlaza distintas épocas. Propone Dóñiz Ibáñez que "en Lost Children Archive, existe una relación diferente entre archivo y repertorio en la que el primero ya no es posterior, sino que, al existir en el presente, se registra al mismo tiempo que se ejecuta y, entonces, se internaliza" (2019: 30). La colocación de unas cajas de mudanzas al principio de cada capítulo refuerza la concepción de la novela como artefacto móvil, como proceso en marcha.

El análisis de las obras de Luiselli muestra, en síntesis, una serie de itinerarios coincidentes. Su escritura aparece ligada a una lógica móvil, radicante, que permea el espacio diegético y el utillaje retórico de sus narraciones. El desplazamiento que he observado, del yo al otro, dibujado en la ruta que lleva de sus primeros textos a los últimos, en el fondo, remite a un mismo problema: el de la pérdida del mundo y de lo humano, y el de la necesidad de poner en marcha otros gestos, otras formas de escucha y reflexión, otras maneras de andar, sentir y hablar, que nos permitan reaprender los espacios que habitamos.

\section{Bibliografía}

Amaro CASTRO, Lorena (2017), “Autobiografía, fábula biográfica y deconstrucción del espacio literario en La historia de mis dientes, de Valeria Luiselli”, en Revista Laboratorio, n. '16, pp. 1-21.

ARNAL, Isabel Verdú (2013), "Vila-Matas, flâneur de la literatura”, en Garcia, Mar (dir.); Blanc, Anne-Lise (dir.); y Badia, Alain (dir.), Géographies du vertige dans l'auvre d'Enrique Vila-Matas, Perpignan, Presses universitaires de Perpignan (generado el 01 junio de 2021). DOI: <https://doi.org/10.4000/books.pupvd.2994>.

BajTín, Mijaíl (1989 [1975]), Teoría y estética de la novela. Kriukova, Helena y Vicente Cazcarra (trad.). Madrid, Taurus.

BARTHES, Roland (2007 [1977]), El placer del texto y lección inaugural. Rosa, Nicolás y Óscar Terán (trads.). Madrid, Siglo XXI. 
Benjamin, Walter (2005 [1983]), Libro de los pasajes. Herrera Baquero, Isidro; Fernández Castañeda, Luis y Fernando Guerrero (trads.). Madrid, Akal.

BOURriaud, Nicolas (2009), Radicante. Buenos Aires, Adriana Hidalgo.

Castany, Bernat (2007), Literatura posnacional. Murcia, Universidad de Murcia. Servicio de Publicaciones.

DóÑIZ IBÁÑEZ, Zyanya (2020), “El archivo encarnado en Lost Children Archive (2019)”, en Lucero, vol. 25, n. ${ }^{\circ} 1$, pp. $28-38$.

ECO, Umberto (1990 [1962]), Obra abierta. Berdagué, Rosé (trad.). Barcelona, Ariel.

ETTE, Ottmar (2008), Literatura en movimiento. Espacio y dinámica de una escritura trasgresora de fronteras en Europa y América. Madrid, Consejo Superior de Investigaciones Científicas.

ETTE, Ottmar (2015), "Desde la filología de la literatura mundial hacia una polilógica filología de las literaturas del mundo", en Müller, Gesine; Gras, Dunia (eds.), América Latina y la literatura mundial: mercado editorial, redes globales y la invención de un continente. Madrid/Frankfurt, Iberoamericana/Vervuert, pp. 323-367.

ESPACIO FUnDACIÓN TELEFÓNICA MADRID (2019), "Encuentro con Valeria Luiselli y Enrique Vila-Matas, en Youtube <https:/www.youtube.com/watch?v=urn4FdHxawc> (17/02/2021).

Foessel, Michaël (2013 [2012]), Después del fin del mundo. Crítica de la razón apocalíptica. Bértolo, Inés (trad.). Barcelona, Península.

LIESBETH, François (2019), "El caminante urbano, heredero reticente: Mis dos mundos de Sergio Chejfec y Papeles falsos de Valeria Luiselli", en Bulletin of Hispanic Studies, vol. 96, n. ${ }^{\circ}$ 8, pp. 851-872. DOI: $<$ https://doi.org/10.3828/bhs.2019.5>.

GARí BARCELÓ, Bernat (2021), "La crisis de los refugiados en Los niños perdidos y Desierto sonoro de Valeria Luiselli”, en Flores Borjabad, Salud Adelaida; Pérez Cabeña, Rosario (coords.), Nuevos retos y perspectivas de la investigación en Literatura, Lingüistica y Traducción. Madrid, Dykinson, pp. 350-364.

GonZÁLEz ArCE, Teresa (2016), "Del ensayo a la novela. Los procesos autoficcionales de Papeles falsos y Los ingrávidos de Valeria Luiselli”, en Sincronía, n. 69 (enero-junio 2016), s/p.

LICATA, Nicolás (2019), "Paradoja de la ceguera vidente y puesta en escena del autor en Los ingrávidos, de Valeria Luiselli, en Transcorporalités, n. ${ }^{\circ}$ 19, s/p. DOI: <https://doi.org/10.4000/amerika.10772>.

Lipovetsky, Gilles (2015 [1983]), La era del vacío. Vinyoli, Joan y Michèle Pendanx (trad.). Barcelona, Anagrama.

LOGIE, Ilse (2020), “Los niños perdidos, de Valeria Luiselli: el intérprete ante las vidas "dignas de duelo"”, en Iberoamericana. América Latina, España, Portugal: ensayos sobre letras, historia y sociedad, vol. 20, n. ${ }^{\circ}$ 75, pp. 103116.

LuISELLI, Valeria (2019), Los ingrávidos. Madrid, Sexto Piso.

LuISELLI, Valeria (2019b), Los niños perdidos (un ensayo en cuarenta preguntas). Madrid, Sexto Piso.

LuISELLI, Valeria (2019c), Desierto sonoro. Madrid, Sexto Piso.

Luiseldi, Valeria (2020), Papeles falsos. Madrid, Sexto Piso.

LuISELLI, Valeria (2020b), La historia de mis dientes. Madrid, Sexto Piso.

MARTínEZ, Antonio (2016), "Valeria Luiselli habla sobre su libro 'Los niños perdidos' y la importancia de la resistencia en la era de Trump", en The New York Times. Consultado en $<$ https://www.nytimes.com/es/2016/12/16/espanol/cultura/valeria-luiselli-ninos-perdidos.html> $(17 / 02 / 2021)$.

MEYER, Lily (2019), “'Archive, Archive, Archive’: Valeria Luiselli on Reading in Order to Write, en Longreads. Consultado en <https://longreads.com/2019/02/12/interview-with-valeria-luiselli > (17/02/2021). 
MORA, Vicente Luis (2014), "Globalización y literaturas hispánicas: de lo posnacional a la novela glocal”, en Pasavento. Revista de Estudios Hispánicos, vol. VI, n. ${ }^{\circ}$ 2, pp. 319-343. DOI: <https://doi.org/10.37536/preh.2014.2.2.1001>.

MORALES MuÑOZ, Brenda (2019), “Reflexiones sobre la migración a partir de 'Los niños perdidos' de Valeria Luiselli, en Diseminaciones, vol. 2, n. 3 (enero-junio 2019), pp. 53-70.

Oliver, María Paz (2019), "La mirada aérea de la flâneuse: el paisaje vertical en Papeles falsos y "Swings of Harlem" de Valeria Luiselli", en Revista Letral, n. ${ }^{\circ}$ 22, pp. 13-29. DOI: $<$ https://doi.org/10.30827/rl.v0i22.9258>.

PAPE, María (2015), "El pasaje como modus operandi: perspectivas simultáneas y recíprocamente excluyentes en Los ingrávidos de Valeria Luiselli", en Revista Chilena de Literatura, n. 90 , pp. 171-195. DOI: <http://dx.doi.org/10.4067/S0718-22952015000200008>.

RAmírez Rojas, Marco (2018), "La historia de mis dientes de Valeria Luiselli: el relato como mercancía, colección y propuesta de archivo", en Hispanófila, n. ${ }^{\circ}$ 183, pp. 333-350. DOI: $<$ http://dx.doi.org/10.1353/hsf.2018.0035>.

Ramos, Julio (2017), “Tierra Blanca. Los zapatos de Elvin (notas sobre el refugio)”, en RECIAL: Revista del Centro de Investigaciones de la Facultad de Filosofía y Humanidades, vol. 8, n. ${ }^{\circ}$ 12, s/p.

SÁNCHEZ ZAPATERO, Javier (2019), "La literatura concentracionaria: universalidad, representación y memoria", en Vegueta. Anuario de la Facultad de Geografia e Historia, n. ${ }^{19}$, pp. 431-455.

SperAnZA, Graciela (2012), Atlas portátil de América Latina. Arte y ficciones errantes. Barcelona, Anagrama.

SONTAG, Susan (2008 [2007]), Al mismo tiempo. Ensayos y conferencias. Major, Aurelio (trad.). Barcelona, Penguin Random House.

Vanden Berghe, Kristine; Licata, Nicolas (2020), “Otro poeta en Nueva York. Gilberto Owen en Los ingrávidos de Valeria Luiselli”, en Literatura mexicana, vol. 31, n. ${ }^{\circ}$ 1, pp. 155-178. DOI: $<$ http://dx.doi.org/10.19130/iifl.litmex.31.1.2020.1150>. 